\title{
A Facile Green Synthesis of Nickel Ferrite Nanoparticles using Tamarindus Indica Seeds for Magnetic and Photocatalytic Studies
}

M MADHUKARA NAIK ( $\sim$ madhukara@mvjce.edu.in )

MVJCE: MVJ College of Engineering https://orcid.org/0000-0002-0135-1035

\section{$M$ Vinuth}

NIE Institute of Technology

\section{Udaya Kumar}

MVJ College of Engineering

\section{K. H. Hemakumar}

Cambridge Institute of Technology

G Preethi

MVJ College of Engineering

\section{Prathap Kumar}

MVJ College of Engineering

\section{G Nagaraju}

Siddaganga Institute of Technology

\section{Research Article}

Keywords: NiFe204, Tamarindus Indica seeds, Microwave method, VSM analysis, Anionic Alizarin red S dye, Methylene blue dye

Posted Date: June 2nd, 2021

DOI: https://doi.org/10.21203/rs.3.rs-568580/v1

License: (a) (1) This work is licensed under a Creative Commons Attribution 4.0 International License. Read Full License 


\title{
A Facile Green Synthesis of Nickel Ferrite Nanoparticles using Tamarindus Indica Seeds for Magnetic and Photocatalytic Studies
}

\author{
M. Madhukara Naik ${ }^{a^{*}}$, M. Vinuth ${ }^{b^{*}}$, V. Udaya Kumara ${ }^{a}$ K.H. Hemakumar ${ }^{c^{*}}$, G. Preethi ${ }^{a}$, \\ M. Prathap Kumara , G. Nagaraju ${ }^{\mathrm{d}}$ \\ ${ }^{a}$ Department of Chemistry, MVJ College of Engineering, Bengaluru 560067 Karnataka, India \\ ${ }^{b}$ Department of Chemistry, NIE Institute of Technology, Mysuru 570 018, Karnataka, India \\ ${ }^{c}$ Department of Chemistry, Cambridge Institute of Technology, Bengaluru 560 036, India \\ ${ }^{d}$ Energy Materials Research Laboratory, Department of Chemistry, Siddaganga Institute of Technology, \\ Tumakuru-572 103, India \\ *Corresponding Authors email ID: madhukara@mvjce.edu.in; vinuthm@nieit.ac.in
}

khhemakumar@gmail.com

\begin{abstract}
:
Magnetic $\mathrm{NiFe}_{2} \mathrm{O}_{4}$ nanoparticle (NFNPs) was synthesized by the microwave-assisted method using Tamarindus indica seeds as a green reducing agent. The identification of NFNPs was carried out by XRD, FTIR, SEM with EDAX analysis, UV-Visible Spectroscopic and luminescence techniques. Spinel structure of NFNPs with a single phase has been confirmed by XRD with an average crystallite size of $21 \mathrm{~nm}$. FTIR confirms the presence of tetrahedral and octahedral sites of prepared NFNPs. SEM with EDAX and TEM gives the information of agglomeration of magnetic nanoparticles with elemental composition present in the NFNPs and spherical nature of nanoparticles with a particle size of $29 \mathrm{~nm}$. The prepared NFNPs are visible active with band gap of $1.92 \mathrm{eV}$. NFNPs show effective photocatalytic activity under visible light irradiation towards the degradation of anionic Alizarin red S dye and cationic Methylene Blue dye. NFNPs show good magnetic property in VSM studies. The prepared NFNPs can be useful for wastewater treatment.
\end{abstract}

Keywords: $\mathrm{NiFe}_{2} \mathrm{O}_{4}$, Tamarindus Indica seeds, Microwave method, VSM analysis, Anionic Alizarin red S dye, Methylene blue dye 


\section{Introduction}

In industrial wastewaters, degradation of dyes has generated a great attention due to low decoloration, slow biodegradation, high toxicity and high volume of production. Every year dyes are produced in large scale and are naturally resistant towards sunlight, water, detergents and other basic chemicals which make them basically difficult to treat [1-2]. These dyes applied to various types of industries including paper, textile, leather, cosmetic, nutrition and pharmaceutical industries. Annually over 700,000 tons of dyes will be produced off which nearly 100,000 different type of dyes are commercially available, during dying process $15 \%$ of which are discharged into the water sources. Azo dyes constitute more than 50\% of these globally produced dyes. These complex aromatic dyes cause severe impact on the human health and aquatic life. These concerns lead to develop new technologies for waste water treatment [2-3].

Recently, due to their optical, magnetic and photocatalytic applications nickel ferrite $\left(\mathrm{NiFe}_{2} \mathrm{O}_{4}\right)$ nanoparticles have attracted very much interest in scientific society. $\mathrm{NiFe}_{2} \mathrm{O}_{4}$ is a soft magnetic material with saturation magnetization $\left(\mathrm{M}_{\mathrm{s}}=40.8 \mathrm{emu} / \mathrm{g}\right)$, coercive field $\left(\mathrm{H}_{\mathrm{c}}=98 \mathrm{Oe}\right)$, remanance magnetization and low electrical resistivity [4]. Generally, in nanoparticles crystallinity, morphology and band gap play an important role in magnetic studies and the photocatalytic applications. Hence, it is a suitable material for magnetic, gas and humidity sensing, catalytic and magneto-optical applications [5]. For the synthesis of $\mathrm{NiFe}_{2} \mathrm{O}_{4}$ nanoparticles several methods have been used which are co-precipitation, sol-gel, combustion, microwave, hydrothermal, and sol-gel auto-combustion methods [6-7]. Among these methods, microwave-assisted method has extended much attention because it is environmentally benign, less reaction time, simple process, and relatively lowers the processing time and temperature which permits to prepare the nanocrystalline ferrite nanoparticles [8]. Table 1 gives the comparative study of green/biosynthesis of $\mathrm{NiFe}_{2} \mathrm{O}_{4} \mathrm{NPs}$. 
Table 1 Biosynthesis of $\mathrm{NiFe}_{2} \mathrm{O}_{4} \mathrm{NPs}$

\begin{tabular}{|l|l|c|l|c|}
\hline Method of synthesis & \multicolumn{1}{|c|}{ Green materials } & $\begin{array}{c}\text { Calcination } \\
\text { temperature }\left({ }^{\circ} \mathbf{C}\right)\end{array}$ & \multicolumn{1}{|c|}{ Morphology } & Ref. \\
\hline Hydrothermal & Urtica extract & - & Rod like platelet & {$[9]$} \\
\hline Sol-gel combustion & Honey-mediated & 1100 & Octahedron & \\
\hline Modified sol-gel & Aloe vera extract & 900 & Agglomerated & {$[10]$} \\
\hline $\begin{array}{l}\text { Simple sol-gel auto- } \\
\text { combustion }\end{array}$ & Onion extract & 750 & Agglomerated & {$[11]$} \\
\hline $\begin{array}{l}\text { Reduction } \\
\text { Desmodium } \\
\text { gangeticum } \text { (Linn) } \\
\text { DC roots }\end{array}$ & - & - & {$[12]$} \\
\hline Hydrothermal & Aloe vera extract & - & Nanoparticles & {$[12]$} \\
\hline $\begin{array}{l}\text { Microwave-assisted } \\
\text { green synthesis }\end{array}$ & $\begin{array}{l}\text { Tamarindus } \text { indica } \\
\text { seeds }\end{array}$ & $\mathbf{6 0 0}$ & Spherical & Present \\
work
\end{tabular}

From the literature, it can be observed that $\mathrm{NiFe}_{2} \mathrm{O}_{4}$ played a vital role in the field of magnetic and photocatalytic applications. Few authors reported the magnetic and photocatalytic studies of $\mathrm{NiFe}_{2} \mathrm{O}_{4}$ NPs. Hirthna et al. has described in the work that $\mathrm{NiFe}_{2} \mathrm{O}_{4} \mathrm{NPs}_{\text {synthesized }}$ by chemical co-precipitation method for photocatalytic degradation of methyl orange dye $(\sim 72.66 \%$ within $5 \mathrm{~h})$. [13]. Andris sutka et al. have prepared the anatase- $\mathrm{NiFe}_{2} \mathrm{O}_{4}$ heterostructures (co-precipitation method) for photocatalytic activity (methyl orange: 96\% degradation after 3 h) [14]. D. Li et al. has synthesized spinel $\mathrm{NiFe}_{2} \mathrm{O}_{4}$ ferrite by sol-gel method for magnetic studies with saturation magnetization $(\mathrm{Ms}=66.6 \mathrm{emu} / \mathrm{g})$, remanenent magnetization $(\mathrm{Mr}=15.9 \mathrm{emu} / \mathrm{g})$ and coercivity $(\mathrm{Hc}=161.6)$ [15].

In the present study, using Tamarindus indica seed powder as a reducing agent, green synthesis of $\mathrm{NiFe}_{2} \mathrm{O}_{4} \mathrm{NPs}$ has been carried out by microwave-assisted method. The as prepared microwave-assisted $\mathrm{NiFe}_{2} \mathrm{O}_{4}$ NPs were characterized by different methods such as XRD, SEM with EDAX, FTIR, TEM, UV-Visible and Luminescence Spectroscopy for photocatalytic (anionic Alizarin red S dye and cationic Methylene blue dye) and magnetic studies. 


\section{Experimental}

\subsection{Materials}

The Tamarindus indica seeds were obtained from a local market of Shivamogga, Karnataka, India. The precursors used are $\mathrm{Fe}\left(\mathrm{NO}_{3}\right)_{3} \bullet 9 \mathrm{H}_{2} \mathrm{O}$ and $\mathrm{Ni}\left(\mathrm{NO}_{3}\right)_{2} \cdot 6 \mathrm{H}_{2} \mathrm{O}$ were obtained from HIMEDIA, India which are used without additional purification and of analytical grade. Throughout the experiment Deionized water was used.

\subsection{Preparation of Tamarind seeds powder}

The collection of dried seeds of Tamarindus indica were washed in tap water to remove the dust particles and then followed by the doubled distilled water for two-three times. After washing, seeds were shaded and dried at room temperature for 10-15 days. After air-dried, seeds were crushed using electric mixture. After crushing, the seeds powder was stored in refrigerator for further analysis.

\subsection{Synthesis of $\mathrm{NiFe}_{2} \mathrm{O}_{4} \mathrm{NPs}$}

$\mathrm{NiFe}_{2} \mathrm{O}_{4} \mathrm{NPs}$ were prepared by taking $\mathrm{Fe}\left(\mathrm{NO}_{3}\right)_{3} \cdot 9 \mathrm{H}_{2} \mathrm{O}$ and $\mathrm{Ni}\left(\mathrm{NO}_{3}\right)_{2} \cdot 6 \mathrm{H}_{2} \mathrm{O}$ with the ratio of 2:1 (Fe:Ni) in extracted Tamarindus indica seed powders with metal nitrates to extract 1:1 ratio in $50 \mathrm{ml}$ deionized water. To get the homogeneous solution the reaction mixture was stirred for about $1 \mathrm{~h}$ and a domestic microwave oven (frequency of $2.54 \mathrm{GHz}$ at $900 \mathrm{~W}$ output power) was used. The solution of reaction mixture was irradiated for $15 \mathrm{~min}$ and the attained product was annealed at $600^{\circ} \mathrm{C}$ for $4 \mathrm{~h}$.

\subsection{Characterization techniques:}

Rigaku Smart Lab XRD (Tokyo, Japan) with $\mathrm{Cu}-\mathrm{K} \alpha$ radiation source $(\lambda=1.5406 \AA$ ) was used for X-ray diffraction (XRD) measurements. To study the two major bond frequencies of nickel ferrite NPs like tetrahedral and octahedral sites was analyzed in the range $4000-350 \mathrm{~cm}^{-1}$ by using Fourier transform infrared spectrum (FTIR) (Bruker alpha-P infrared spectrophotometer). Zeiss electron microscope was used to observe the surface morphologies of the samples like scanning electron microscopy (SEM) and elemental analysis. For shape and morphological observation Field Emission Gun-Transmission Electron Microscope $300 \mathrm{kV}$ was used. Shimadzu UV-Visible spectroscopy was used for optical studies. During degradation, 
Agilent technology Cary-60 spectrophotometer was used for the absorbance of the organic dye. Agilent technology Cary Eclipse Spectrofluorometer was used for luminescence studies.

\subsection{Photocatalytic degradation procedure:}

Photodegradation of anionic Alizarin red S (ARS) dye and cationic Methylene blue (MB) dye under visible light irradiation in presence of microwave-assisted $\mathrm{NiFe}_{2} \mathrm{O}_{4} \mathrm{NPs}$ was evaluated. In a photoreactor, $50 \mathrm{mg}$ of $\mathrm{NiFe}_{2} \mathrm{O}_{4}$ photocatalyst was added to a quartz tube containing $100 \mathrm{~mL}$ of 20 ppm anionic ARS dye and cationic MB dye aqueous solution. In dark condition to attain the adsorption/desorption equilibrium the reaction mixture was stirred in dark for $30 \mathrm{~min}$. At room temperature, the solution (reaction mixture) was irradiated under visible light. The degradation residual was collected every 30 min and was tested by UV-Vis absorption spectra at the absorbance of $525 \mathrm{~nm}(\mathrm{ARS})$ and $663 \mathrm{~nm}(\mathrm{MB})$. By the following relation the photocatalytic degradation percentage of dyes was measured,

$$
\text { percentage of degradation }=\frac{C_{o}-C_{t}}{C_{o}} \times 100
$$

Where, $C_{o}$ is the initial absorbance of aliquot and $C_{t}$ is the absorbance of anionic ARS dye aliquot after time $\mathrm{t}$ in min, respectively.

\section{Results and Discussion}

\subsection{XRD analysis}

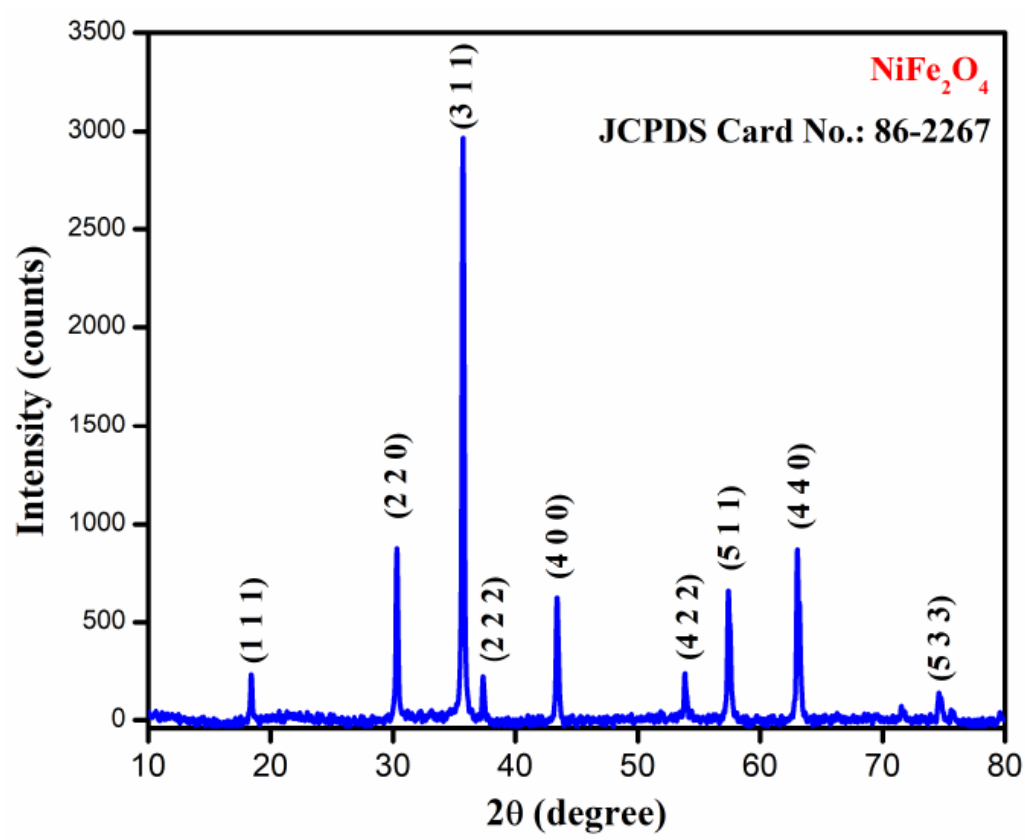

Fig. 1 XRD pattern of microwave-assisted $\mathrm{NiFe}_{2} \mathrm{O}_{4} \mathrm{NPs}$ 
XRD pattern of microwave-assisted $\mathrm{NiFe}_{2} \mathrm{O}_{4}$ nanoparticles was shown in Fig. 1 and the spinel structure with single phase material was confirmed with JCPDS No. 86-2267. DebyeScherrer's formula was used to determine the average crystallite size of $\mathrm{NiFe}_{2} \mathrm{O}_{4} \mathrm{NPs}$ and was estimated as $21 \mathrm{~nm}$,

$$
D=\frac{0.9 \lambda}{\beta \operatorname{Cos} \theta}
$$

Where, $\lambda$ is wavelength of radiation source (1.5406 $\AA$ ) and $\beta$ is the full width half maximum.

By the following formula it was calculated that Dislocation density of $\mathrm{NiFe}_{2} \mathrm{O}_{4} \mathrm{NPs}_{\text {sas }}$ found to be $2.2675 \times 10^{15}$ lines $/ \mathrm{m}^{2}$,

$$
\delta=1 / \mathrm{D}^{2}
$$

Microstrain of green synthesized $\mathrm{NiFe}_{2} \mathrm{O}_{4}$ NPs was $4.96 \times 10^{-2}$ and was found by following relation,

$$
\mu=\frac{\beta \operatorname{Cos} \theta}{4}
$$

\subsection{Morphological analysis}

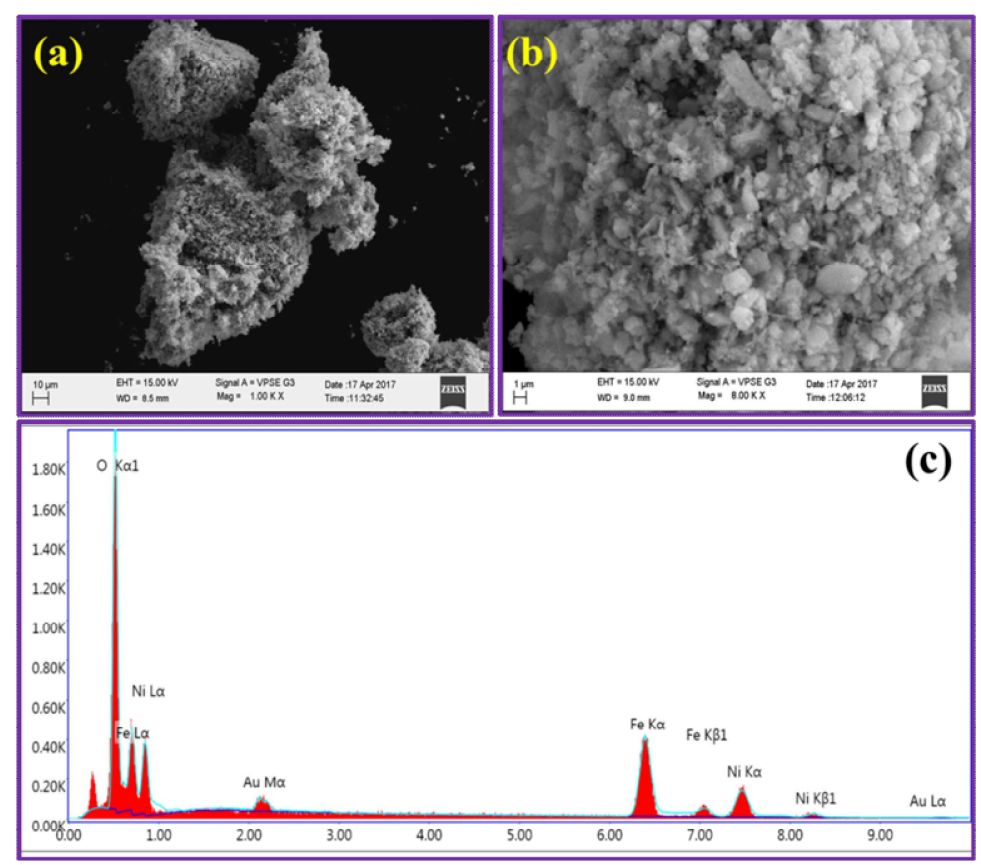

Fig. 2 (a) \& (b) SEM images and (c) EDAX pattern of microwave-assisted $\mathrm{NiFe}_{2} \mathrm{O}_{4} \mathrm{NPs}$ 


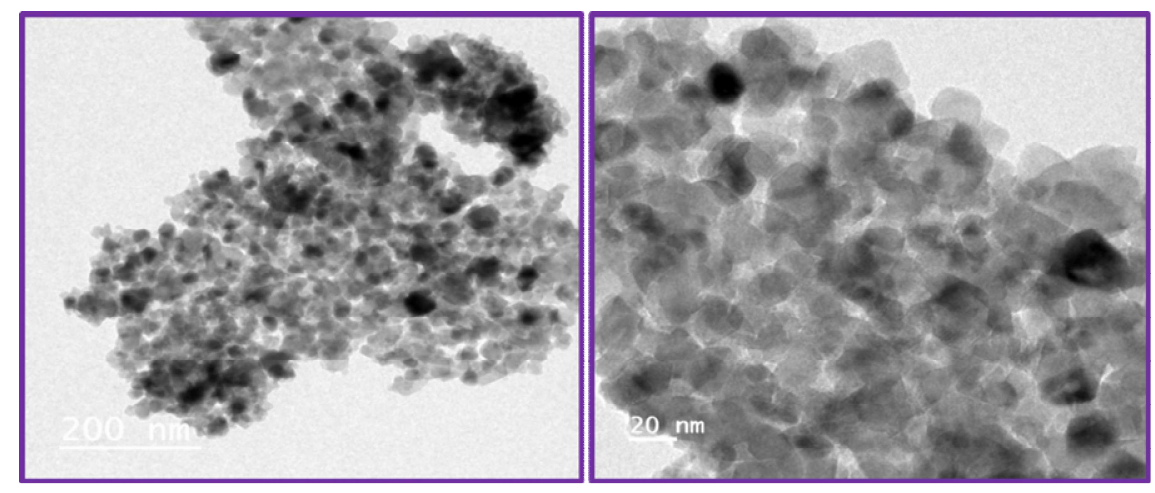

Fig. 3 TEM images of microwave-assisted $\mathrm{NiFe}_{2} \mathrm{O}_{4} \mathrm{NPs}$

Fig. 2a \& 2b showed the SEM micrograph of microwave-assisted $\mathrm{NiFe}_{2} \mathrm{O}_{4} \mathrm{NPs}_{\text {shere }}$ whe agglomerated with uniform distribution of NPs and also narrow size distribution of NPs observed. During microwave combustion process the high energy generated leads to the agglomeration of $\mathrm{NiFe}_{2} \mathrm{O}_{4}$ NPs. TEM micrograph (Fig. 3) showed the uniform formation spherical NF nanoparticles. The chemical elemental compositions of prepared $\mathrm{NiFe}_{2} \mathrm{O}_{4} \mathrm{NPs}_{\text {was }}$ observed in EDAX spectrum. The characteristic peaks of elements $\mathrm{Ni}, \mathrm{Fe}$ and $\mathrm{O}$ are present in the Fig. $2 \mathrm{c}$ and also it showed that there is no impurities present in the prepared $\mathrm{NiFe}_{2} \mathrm{O}_{4} \mathrm{NPs}_{\text {. }}$

\subsection{FTIR analysis}

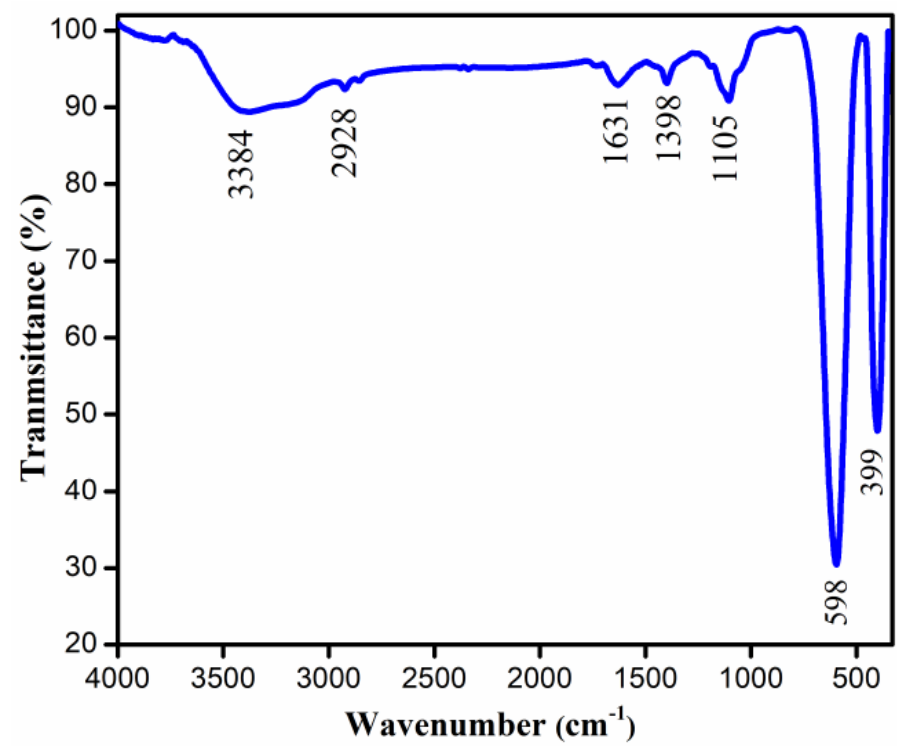

Fig. 4 FTIR Spectrum of microwave-assisted $\mathrm{NiFe}_{2} \mathrm{O}_{4} \mathrm{NPs}$

FT-IR spectrum of microwave-assisted $\mathrm{NiFe}_{2} \mathrm{O}_{4}$ NPs (Fig. 4) recorded in the range between 4000-350 $\mathrm{cm}^{-1}$. Spinel ferrite have two main frequencies of absorption bands in those 
two the absorption band at $\sim 598 \mathrm{~cm}^{-1}$ assigned between $\mathrm{Ni}-\mathrm{O}$ in tetrahedral sites which occurs due to intrinsic stretching vibration of bonds. The weakest absorption peak observed at $\sim 399 \mathrm{~cm}^{-}$ ${ }^{1}$ assigned to the stretching vibration of bonds between Fe-O in octahedral sites. The weak band at 2928 and $1398 \mathrm{~cm}^{-1}$ corresponds to stretching vibration of $\mathrm{C}-\mathrm{H}$ group. The band at 3384 and $1631 \mathrm{~cm}^{-1}$ is attributed to the stretching vibration of $\mathrm{H}-\mathrm{O}-\mathrm{H}$ groups of water molecules adsorbed. The corresponding absorbed Carbon dioxide on the surface of $\mathrm{NiFe}_{2} \mathrm{O}_{4}$ NPs was observed at $1105 \mathrm{~cm}^{-1}$ [16]. Based on the overhead results, the ferrite structure expected can be concluded.

\subsection{Optical studies}
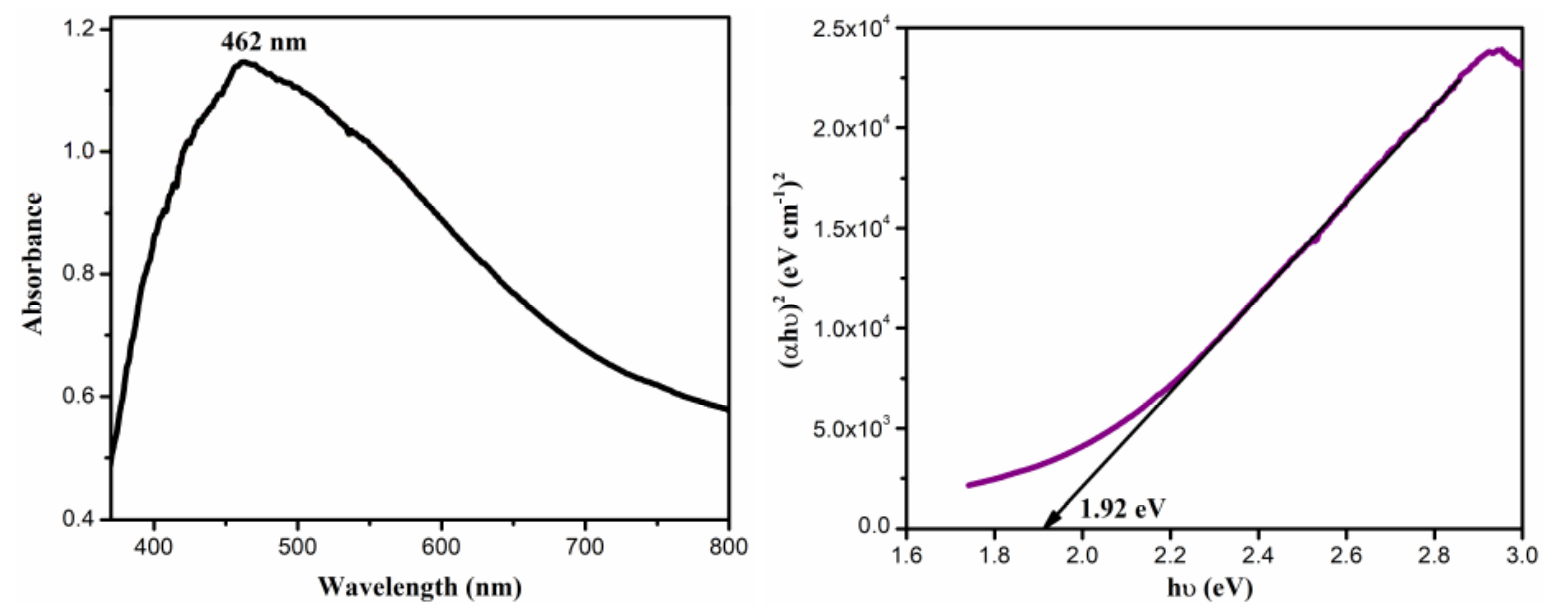

Fig. $5 \mathrm{UV}-\mathrm{Vis}$ absorbance and band gap of microwave-assisted $\mathrm{NiF}_{2} \mathrm{O}_{4} \mathrm{NPs}$

Fig. 5 showed the optical absorption spectrum of $\mathrm{NiFe}_{2} \mathrm{O}_{4} \mathrm{NPs}$. The absorption edge of the $\mathrm{NiFe}_{2} \mathrm{O}_{4} \mathrm{NPs}$ was observed at $460 \mathrm{~nm}$. The fundamental absorption calculations was used for the optical energy band gap calculation and was calculated by the relation [17]

$$
(\alpha h v)^{1 / n}=A\left(h v-E_{g}\right)
$$

Where $\mathrm{A}$ is a constant, $\mathrm{E}_{\mathrm{g}}$ is the band gap of the material and the exponential $\mathrm{n}$ depends on the transition type. For direct allowed transition the parameter $\mathrm{n}$ with value 2 can be used and for indirect allowed transition $1 / 2$ can be used. Tauc plot between $(\alpha h v)^{2}$ and energy (hv) are plotted and the linear straight line which meets the energy axis was extrapolated to obtain the energy bandgap (Fig 5). The optical energy band gap of $\mathrm{NiFe}_{2} \mathrm{O}_{4} \mathrm{NPs}$ was found to be $1.92 \mathrm{eV}$. The obtained result matched nearly with the literature and the materials is visible active [18]. 


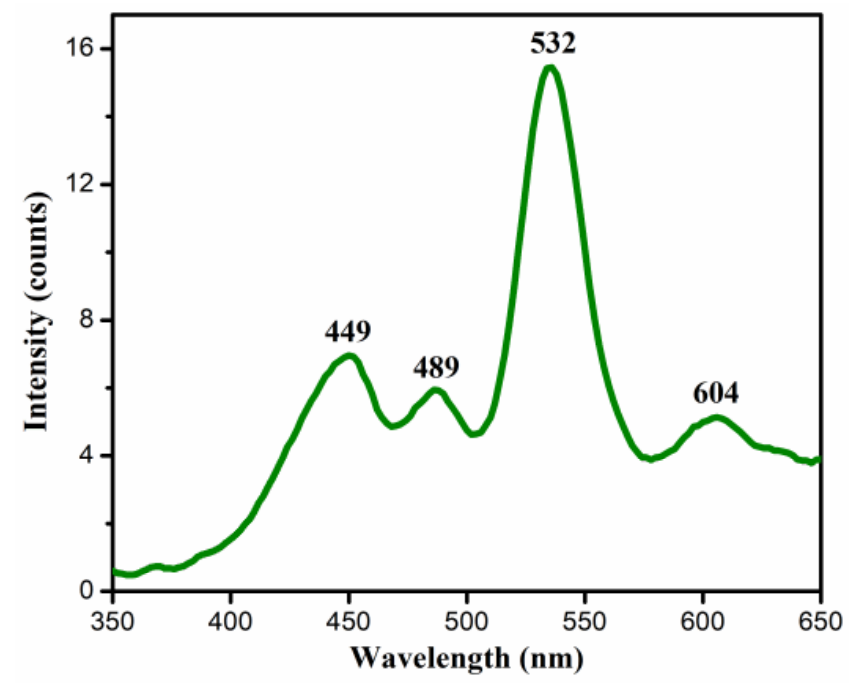

Fig. 6 Luminescence spectrum of microwave-assisted $\mathrm{NiF}_{2} \mathrm{O}_{4} \mathrm{NPs}$

The luminescence spectrum of the microwave-assisted $\mathrm{NiF}_{2} \mathrm{O}_{4}$ NPs can be observed in Fig. 6 at an excitation wavelength of $230 \mathrm{~nm}$. In the visible region it exhibits violet, blue, green and orange emission at 449, 489, 532 and $604 \mathrm{~nm}$. The sharp peaks in the spectra are assigned to the transfer of charges at octahedral sites between $\mathrm{Fe}^{3+}$ and surrounded $\mathrm{O}^{2-}$ ions. The peak at 532 $\mathrm{nm}$ attributed to the recombination of photo-generated holes from nickel interstitials and oxygen vacancies which are originated from the near band gap emission with ionized charged species. The blue green emission of $\mathrm{NiF}_{2} \mathrm{O}_{4}$ NPs can be confirmed by electron transition from deep donor level oxygen vacancies to the valence band [19-20].

\subsection{Magnetic studies}

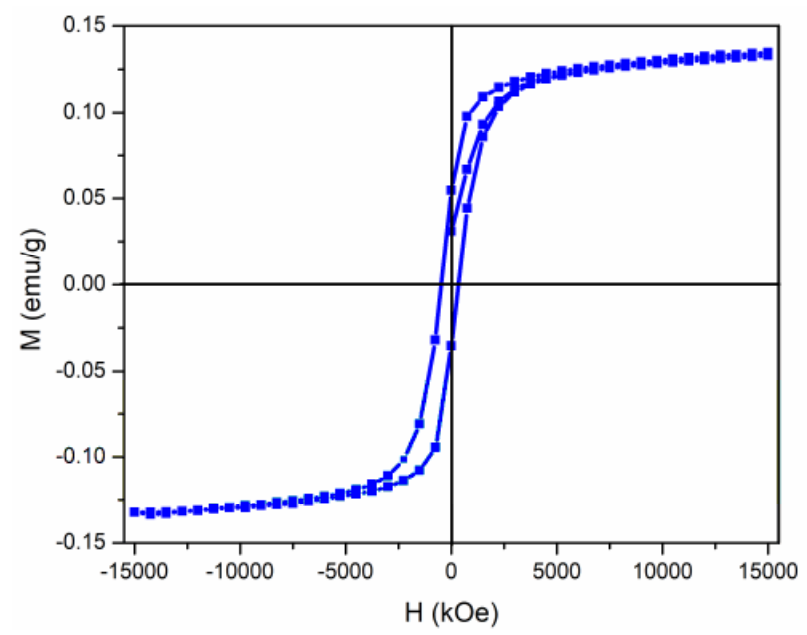

Fig. 7 Magnetization hysteresis loop of microwave-assisted $\mathrm{NiF}_{2} \mathrm{O}_{4} \mathrm{NPs}$ 
The magnetic properties $\mathrm{NiF}_{2} \mathrm{O}_{4}$ NPs were characterized using a vibrating sample magnetometer (VSM) with an applied magnetic field -15000 of +15000 Oe at room temperature. The microwave-assisted $\mathrm{NiF}_{2} \mathrm{O}_{4} \mathrm{NPs}$ confirmed as ferromagnetic (soft magnetic) from Fig. 7 which shows the plot of magnetization versus applied field $(\mathrm{M}-\mathrm{H})$ loop. The remanent magnetization $\left(M_{r}\right)$, saturation magnetization $\left(M_{s}\right)$ and coercivity $\left(H_{c}\right)$ of $\mathrm{NiFe}_{2} \mathrm{O}_{4}$ nanoparticles are $12.27 \mathrm{emu} / \mathrm{g}, 35.13 \mathrm{emu} / \mathrm{g}, 1230 \mathrm{Oe}$, respectively [21, 22]. These results confirmed that the prepared NPs will become a renewable photocatalyst because by using an external magnetic field the photocatalyst can be removed effectively from the aqueous solution of reaction mixture.

\subsection{Photocatalytic activity}

The photodegradation of anionic ARS dye $(\lambda=525 \mathrm{~nm})$ and cationic MB dye $(\lambda=663$ $\mathrm{nm}$ ) in the presence of microwave-assisted $\mathrm{NiF}_{2} \mathrm{O}_{4}$ NPs has been assessed under visible light (Fig. 8). The absorbance of anionic ARS dye solution was decreased with increasing visible light irradiation time. The absorbance of anionic ARS dye cationic MB dye has drastically decreased and gives $83 \%$ and $82 \%$ of degradation in $120 \mathrm{~min}$.

Microwave-assisted $\mathrm{NiF}_{2} \mathrm{O}_{4}$ nanoparticles mainly depends crystalline nature, charge separation and on the distinctive surface morphology (SEM and TEM). The degradation of anionic ARS dye and cationic MB dye follows the pseudo first order kinetic from the kinetic studies which was confirmed by the relation,

$$
C_{t}=C_{0} e^{-K t}
$$

Alternatively

$$
\ln \left(\frac{C_{0}}{C_{t}}\right)=K t
$$

Where, $\mathrm{C}_{0}$ is the initial concentration, $\mathrm{C}_{\mathrm{t}}$ is the concentration of aqueous solution of anionic ARS dye at time $\mathrm{t}$ and $\mathrm{K}$ is the rate constant $\left(\mathrm{min}^{-1}\right)$. The obtained first-order rate constant of $\mathrm{NiF}_{2} \mathrm{O}_{4}$ photocatalyst was $6.02 \times 10^{-3} \mathrm{~min}^{-1}$. 

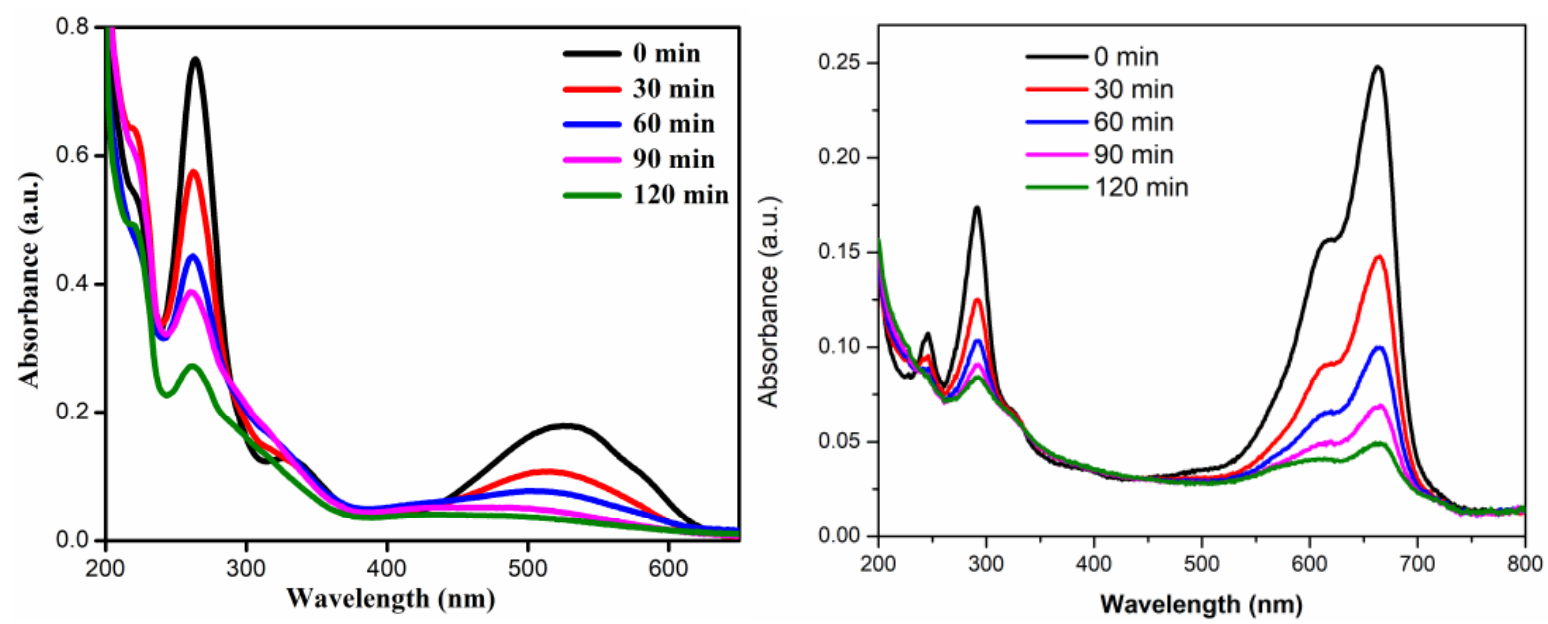

Fig. 8 Photocatalytic absorbance spectrum of anionic ARS dye and cationic MB dye in presence of microwave-assisted $\mathrm{NiFe}_{2} \mathrm{O}_{4} \mathrm{NPs}$

\subsection{Photocatalytic degradation mechanism}

Following equations shows the degradation mechanism of anionic ARS dye cationic MB dye solution in the presence of $\mathrm{NiFe}_{2} \mathrm{O}_{4}$ photocatalyst,

$$
\begin{aligned}
& \mathrm{NiFe}_{2} \mathrm{O}_{4}+\mathrm{hv}(\mathrm{Vis}) \longrightarrow \mathrm{NiFe}_{2} \mathrm{O}_{4}\left(\mathrm{e}_{\mathrm{CB}}^{-}+\mathrm{h}^{+}{ }_{\mathrm{VB}}\right) \\
& \mathrm{NiFe}_{2} \mathrm{O}_{4}\left(\mathrm{e}_{\mathrm{CB}}^{-}\right)+\mathrm{O}_{2} \longrightarrow{ }^{\cdot} \mathrm{O}_{2}^{-} \\
& \mathrm{H}_{2} \mathrm{O} \longrightarrow \mathrm{H}^{+}+\mathrm{HO}^{-} \\
& \mathrm{HO}^{-}+\mathrm{h}^{+} \longrightarrow \mathrm{HO}^{\bullet} \\
& \mathrm{O}_{2}^{-}+\mathrm{H}^{+} \leftrightarrow \mathrm{HOO}^{\bullet} \\
& \mathrm{HOO}^{\bullet}+\mathrm{e}^{-} \longrightarrow \mathrm{HOO}^{-} \\
& \mathrm{HOO}^{-}+\mathrm{H}^{+} \longrightarrow \mathrm{H}_{2} \mathrm{O}_{2} \\
& \mathrm{H}_{2} \mathrm{O}_{2}+\mathrm{e}^{-} \longrightarrow \mathrm{HO}^{\bullet}+\mathrm{HO}^{-} \\
& \mathrm{NiFe}_{2} \mathrm{O}_{4}\left(\mathrm{~h}^{+}{ }_{\mathrm{VB}}\right)+\mathrm{H}_{2} \mathrm{O} \longrightarrow \mathrm{HO}^{\bullet}+\mathrm{H}^{+} \\
& \text {Dye }(\text { ARS \& } \mathrm{MB})+\mathrm{HO}^{\circ} \longrightarrow \mathrm{CO}_{2}+\mathrm{H}_{2} \mathrm{O} \text { (Byproduct) } \\
& \text { Dye }+\mathrm{NiFe}_{2} \mathrm{O}_{4}\left(\mathrm{~h}^{+} \mathrm{VB}\right) \longrightarrow \text { Oxidation product }
\end{aligned}
$$




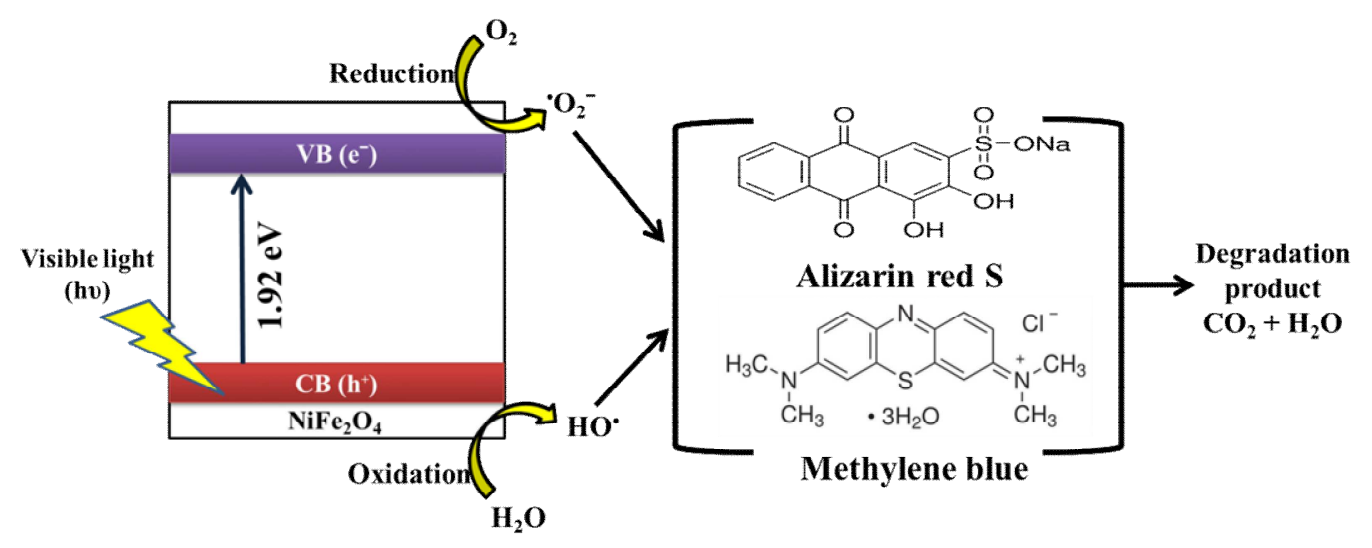

Fig. 9 Photocatalytic degradation mechanism of anionic ARS dye cationic MB dye in presence of microwave-assisted $\mathrm{NiFe}_{2} \mathrm{O}_{4} \mathrm{NPs}$.

In the photodegradation process of the anionic ARS dye cationic $\mathrm{MB}$ dye ${ }^{\circ} \mathrm{OH}$ and ${ }^{\circ} \mathrm{O}_{2}{ }^{-}$ are the notable reactive species (Fig. 9). Photocatalytic degradation efficiency of anionic ARS dye of microwave-assisted $\mathrm{NiFe}_{2} \mathrm{O}_{4}$ NPs compared with some other metal oxide NPs given in Table 2.

Table 2 Photocatalytic degradation efficiency (anionic ARS dye) of microwave-assisted $\mathrm{NiFe}_{2} \mathrm{O}_{4}$ nanoparticles compared with some other metal oxide NPs

\begin{tabular}{|c|c|c|c|}
\hline Sample & Source & $\begin{array}{l}\text { Degradation } \\
\text { efficiency }(\%)\end{array}$ & Ref. \\
\hline $\mathrm{ZnO}$ & UV & 77 & {$[23]$} \\
\hline $\mathrm{ZnO}$ & Sunlight & 51.62 & {$[24]$} \\
\hline $\mathrm{SnO}_{2}$ & Sunlight & 46.29 & {$[24]$} \\
\hline ZnO (prismatic tip) & UV light & 66 & {$[25]$} \\
\hline ZnO (nanobuds) & UV light & 70 & {$[25]$} \\
\hline $\mathrm{ZnS}$ & Sunlight & 50 & {$[26]$} \\
\hline $\mathrm{TiO}_{2}$ & Visible light & 50 & [27] \\
\hline $3 \% \mathrm{Bi}$ doped $\mathrm{TiO}_{2}$ & Visible light & 78 & {$[27]$} \\
\hline $5 \% \mathrm{Bi}$ doped $\mathrm{TiO}_{2}$ & Visible light & 75 & [27] \\
\hline $\mathrm{NiFe}_{2} \mathrm{O}_{4}$ & Visible light & 83 & Present work \\
\hline
\end{tabular}




\section{Conclusion}

Microwave-assisted green method was used to synthesis the $\mathrm{NiFe}_{2} \mathrm{O}_{4}$ NPs using Tamarindus indica seed powder as an reducing agent. XRD confirmed the spinel structure with single phase of $\mathrm{NiFe}_{2} \mathrm{O}_{4}$ nanoparticles with an average crystallite size of $21 \mathrm{~nm}$. The presence of tetrahedral $\left(598 \mathrm{~cm}^{-1}\right)$ and octahedral $\left(399 \mathrm{~cm}^{-1}\right)$ sites in ferrite NPs was observed in the prepared sample by FTIR analysis. The agglomeration of magnetic nanoparticles and the presence of elemental compositions were observed in SEM images and EDAX spectrum. TEM image showed the spherical nature of $\mathrm{NiFe}_{2} \mathrm{O}_{4}$ nanoparticles with particle size of $29 \mathrm{~nm}$. It was confirmed that the sample was visible active because the optical band gap was $1.92 \mathrm{eV}$ and green emission around $532 \mathrm{~nm}$ was observed in luminescence spectrum. Microwave-assisted $\mathrm{NiFe}_{2} \mathrm{O}_{4}$ nanoparticles showed significant photocatalytic (anionic ARS dye and cationic MB dye) and Magnetic studies. Biosynthesized $\mathrm{NiFe}_{2} \mathrm{O}_{4}$ NPs are the appropriate material for optical studies, wastewater treatment and magnetic studies.

\section{Acknowledgement}

The author Dr. M. Madhukara Naik thanks Shri. M.J. Balachandar (Chairman), The Principal, Vice Principal, MVJ College of Engineering for encouraging the research activity. Dr. M. Vinuth thanks to the Principal and Board of Management, NIE Institute of Technology for encouraging the research activity. 


\section{References:}

[1] Pattnaik S P, Behera A, Martha S, Acharya R, Parida K, 2018 J. Nanopart. Res., 2010

[2] Soltani T, Entezari M H, 2013 Chem. Eng. J., 223145

[3] Khataee A, Kasiri M B, 2010 J. Mol. Catal. A: Chem., 3288

[4] Lassoued A, Lassoued M S, Dkhil B, Ammar S, Gadri A, 2018 J. Mater. Sci.: Mater. Electron., 297057

[5] Umut E, Cokun M, Pineider F, Berti D, Gungunes H, 2019 J. Colloid Interface Sci. $\mathbf{5 5 0} 199$

[6] He J, Yang S, Riisager A, 2018 Catal. Sci. Technol., 8790

[7] Joshi S, Kumar M, Chhoker S, Srivastava G, Jewariya M, Singh V N, 2014 J. Mol. Struct., 107655

[8] Kombaiah K, Vijaya J J, Kennedy L J, Kaviyarasu K, 2019 Mater. Chem. Phys., 221 11

[9] Yadav R S, Kurtka I, Vilcakova J, Havlica J, Masilko J, Kalina L, Tkacz J, Enev V, Hajduchova M, 2017 J. Phys. Chem. Solids, 107150

[10] Laokul P, Amornkitbamrung V, Seraphin S, Maensiri S, 2011 Curr. Appl. Phy., 11 101

[11] Ansari F, Bazarganipour M, Salavati-Niasari M, 2016 Mat. Sci. Semicon. Proc., 4334

[12] Sudhasree S, Banu A S, Brindha P, Kurian G A, 2014 Toxicol. Environ. Chem., 96743

[13] Hirthna, Sendhilnathan S, Rajan P I, Adinaveen T, 2018 J. Supercon. Nov. Magn., 31 3315

[14] Sutka A, Millers M, Dobelin N, Parna R, Vanags M, Maiorov M, Kleperis J, Kaambre T, Joost U, Nommiste E, Kisand V, Knite M, 2015 Phys. Status Solidi (a), 212796

[15] Li D, Sun Y, Gao P, Zhang X, Ge H, 2014 Ceram. Int. 4016529

[16] Liu S, Feng L, Xu N, Chen Z, Wang X, 2012 Chem. Eng. J., 203432

[17] Kumari C, Dubey H K, Naaz F, Lahiri P, 2020 Phase Transit. 93207

[18] Karmakar S, Behera D, 2020 Nov. Magn. 331619

[19] Singh R K, Narayan A, Prasad K, Yadav R S, Pandey A C, Singh A K, Verma L, Verma R K, 2012 J. Therm. Anal. Calorim. 110573

[20] Saranya R, Raj R A, AlSalhi M S, Devanesan S, 2018 J. Supercond. Novel Magn., 31 1219 
[21] Godbole B, Badera N, Shrivastava S B, Jain D, Chandra L S S, Ganesan V, 2013 Phys. Procedia, 4958

[22] Vigneswari T, Raji P, 2019 Inorg. Nano-Met. Chem., 354

[23] Kansal S K, Lamba R, Mehta S K, Umar A, 2013 Mater. Lett., 106385

[24] Bouchaaba H, Bellal B, Trari M, 2018 Theor. Exp. Chem., 53417

[25] Sharma S C, 2016 Optik, 1276498

[26] Jabeen U, Shah S M, Khan S U, 2017 Surf. Interfaces, 640

[27] Sood S, Mehta S K, Umar A, Kansal S K, 2014 New J. Chem., 383127 
Figures

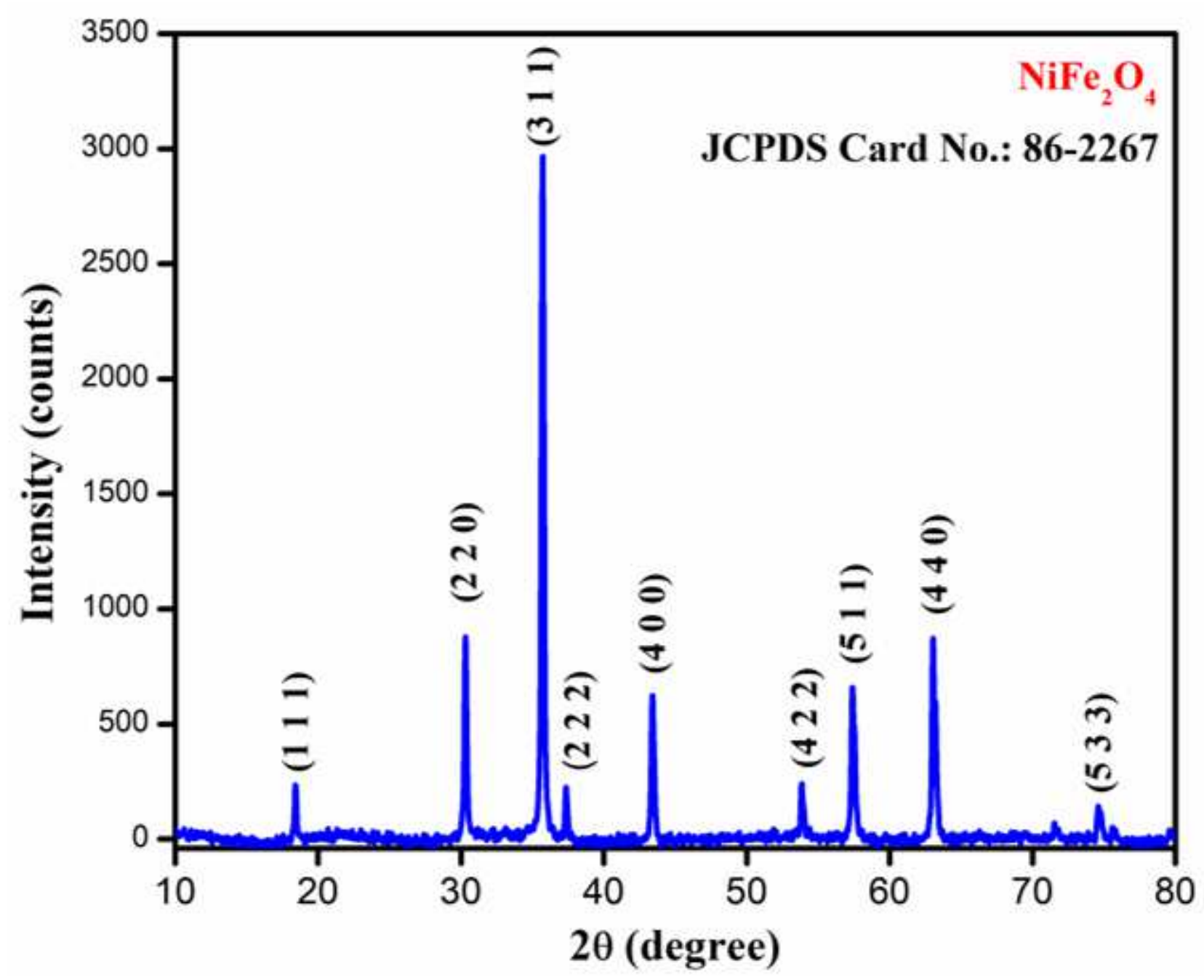

Figure 1

XRD pattern of microwave-assisted NiFe204 NPs 

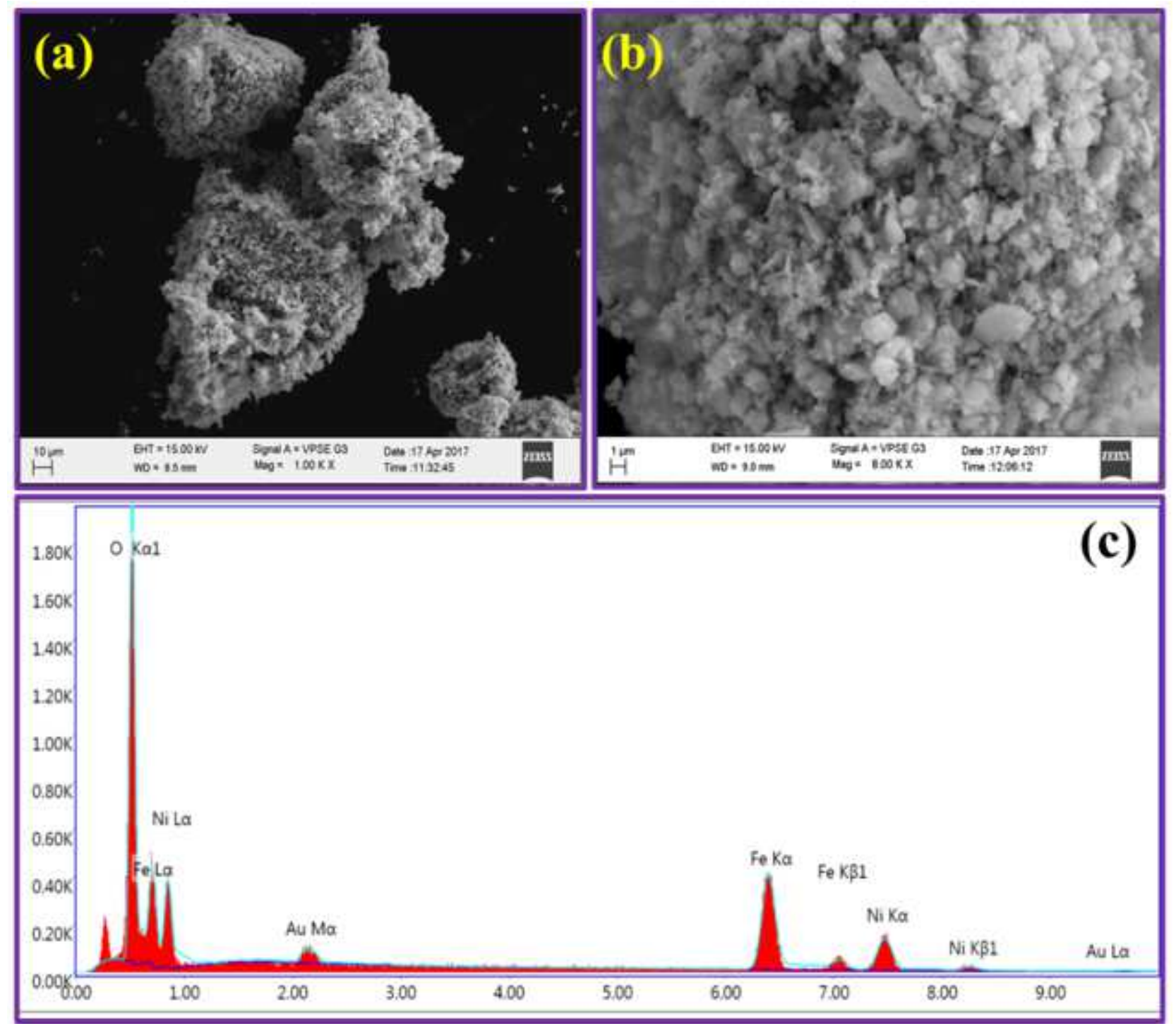

Figure 2

(a) \& (b) SEM images and (c) EDAX pattern of microwave-assisted NiFe204 NPs
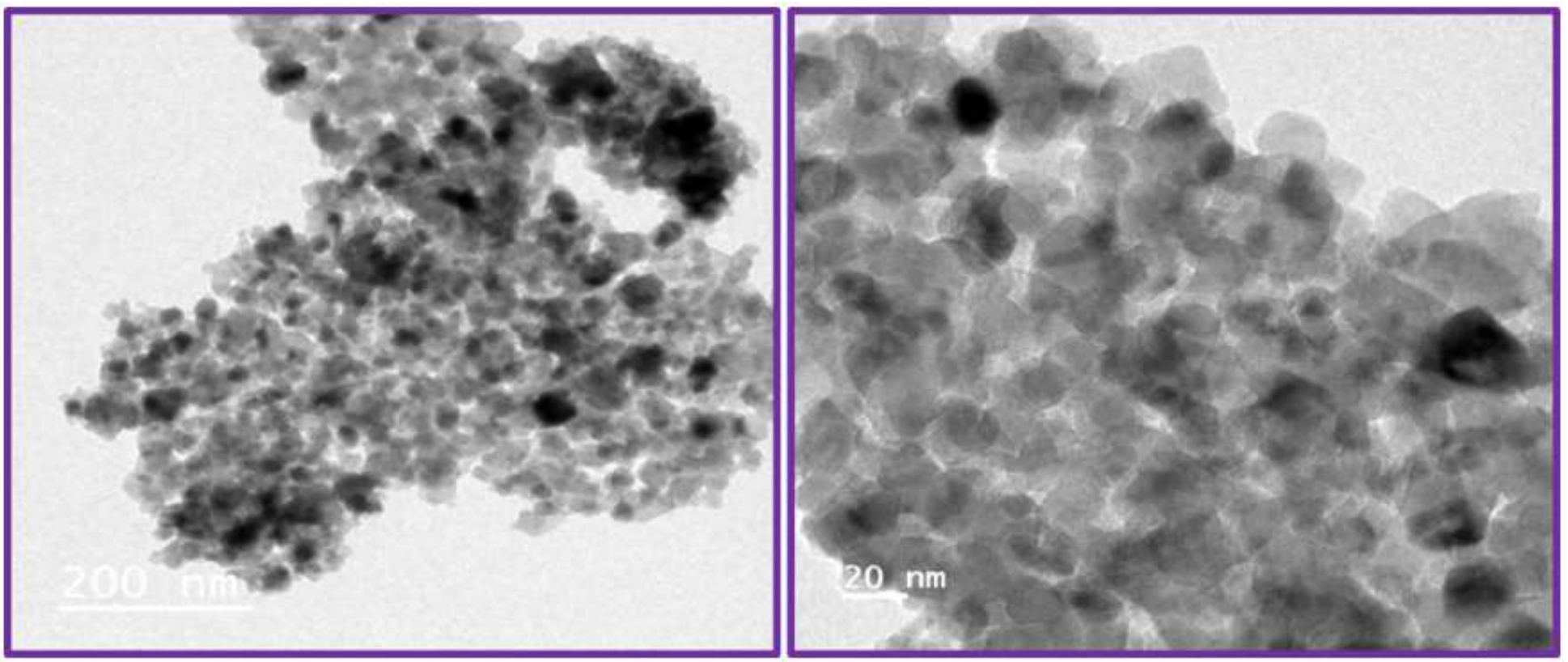
Figure 3

TEM images of microwave-assisted NiFe204 NPs

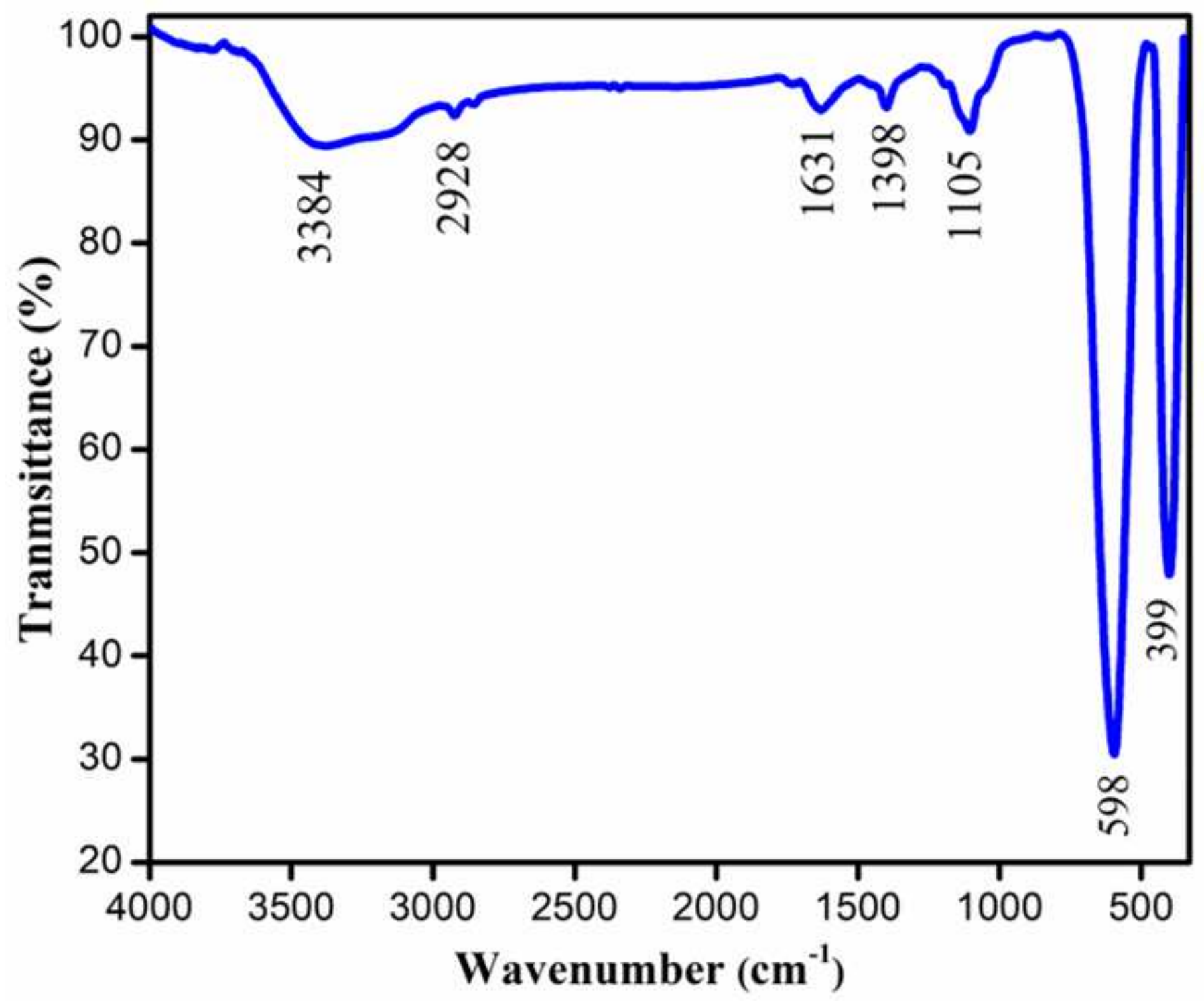

Figure 4

FTIR Spectrum of microwave-assisted NiFe204 NPs 

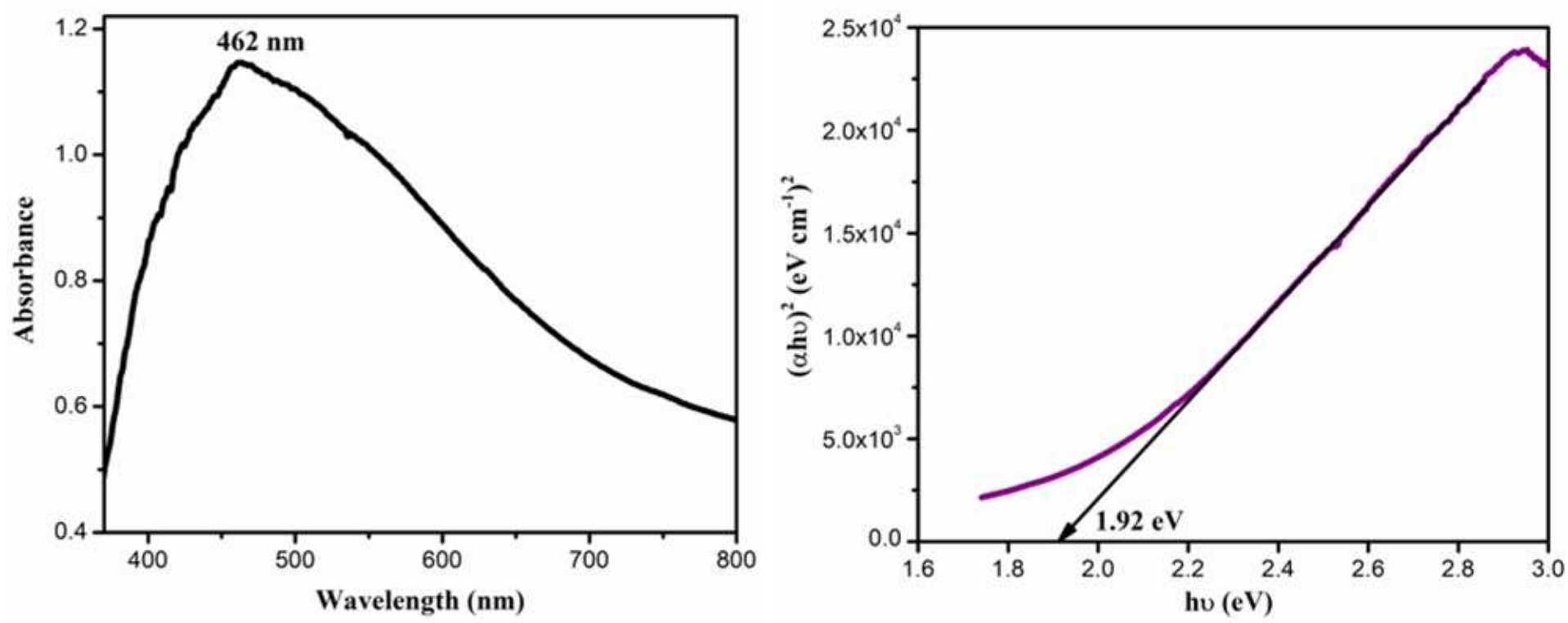

Figure 5

UV-Vis absorbance and band gap of microwave-assisted NiF204 NPs

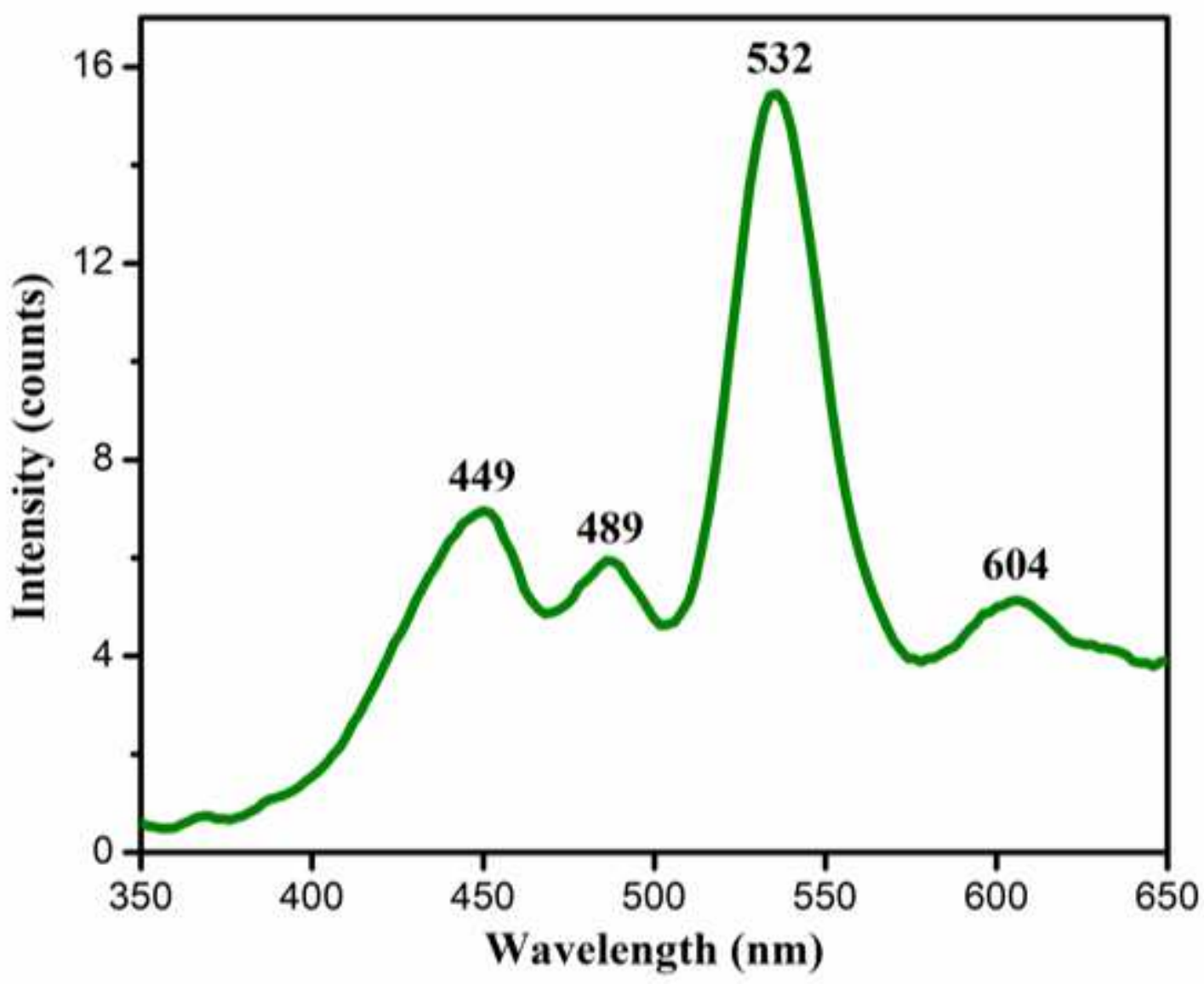

Figure 6

Luminescence spectrum of microwave-assisted NiF204 NPs 


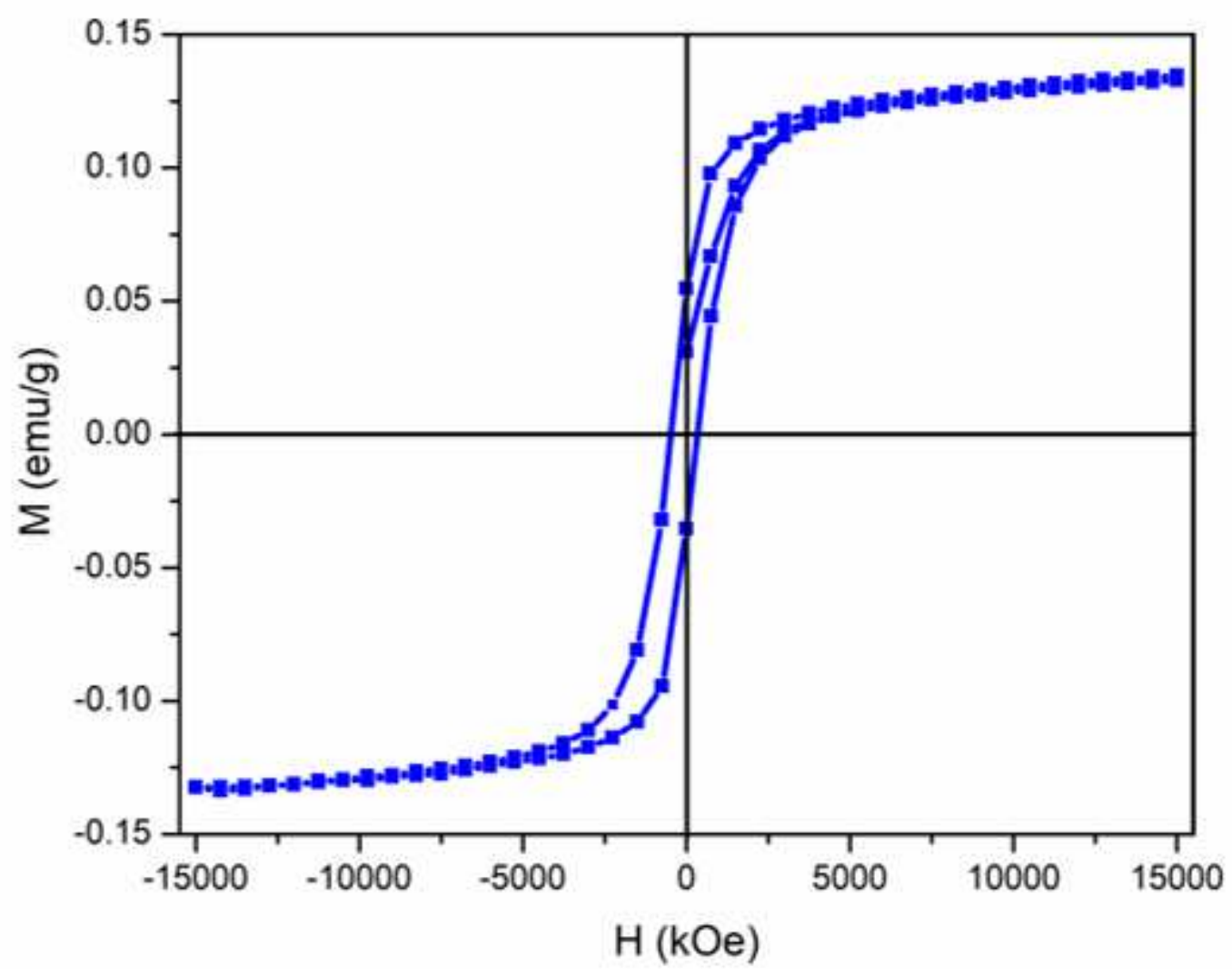

Figure 7

Magnetization hysteresis loop of microwave-assisted NiF204 NPs
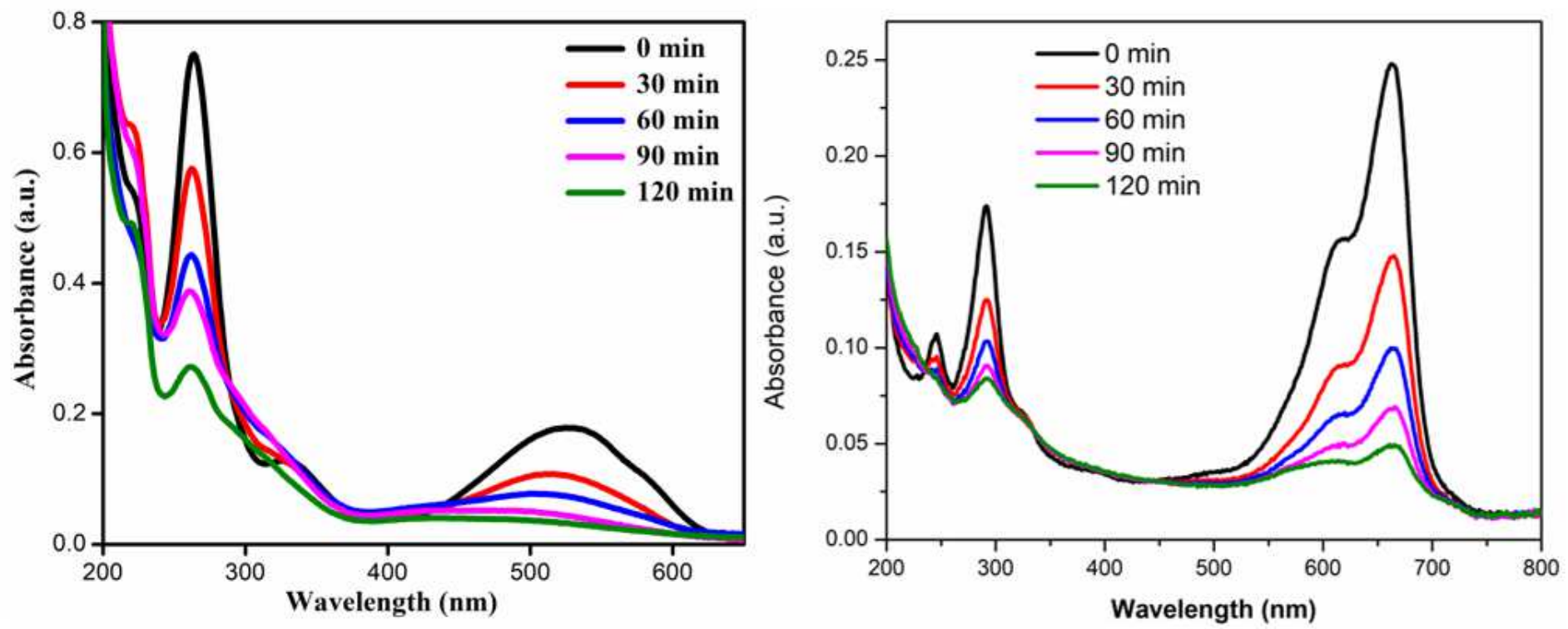

Figure 8

Photocatalytic absorbance spectrum of anionic ARS dye and cationic MB dye in presence of microwaveassisted NiFe204 NPs 


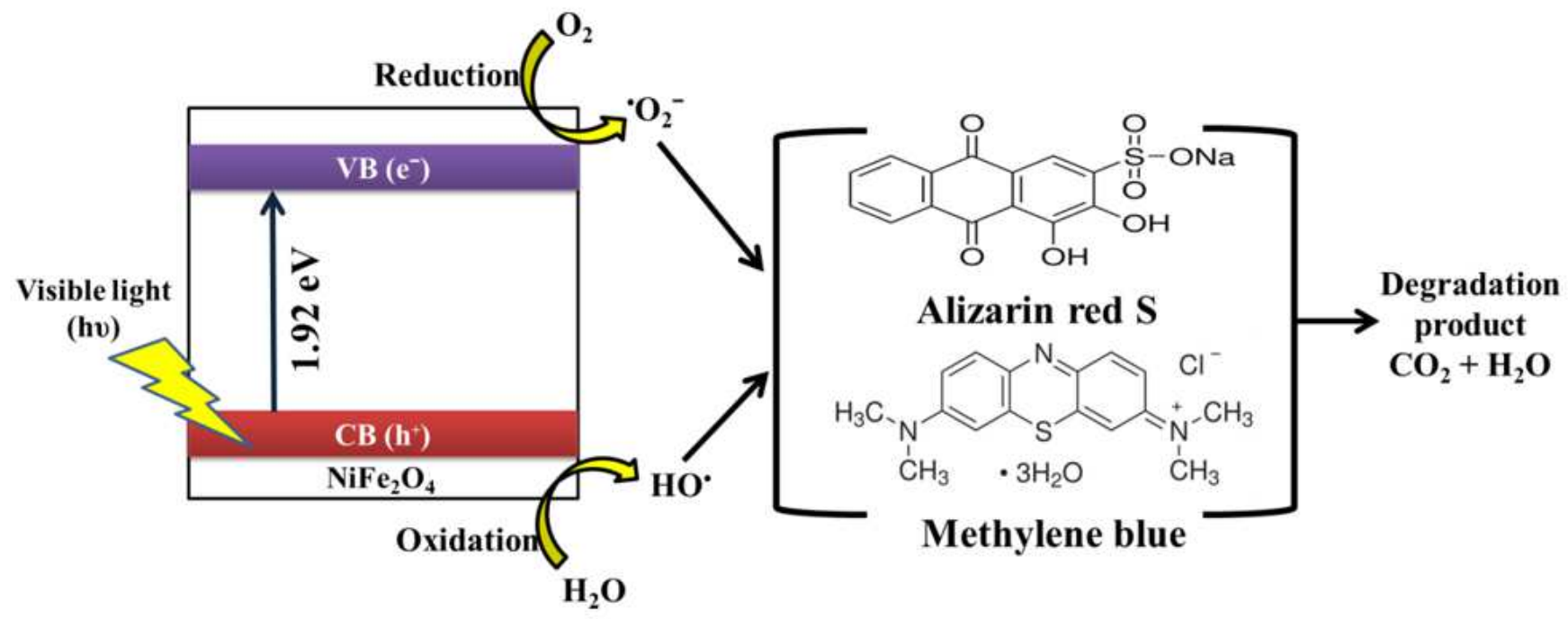

Figure 9

Photocatalytic degradation mechanism of anionic ARS dye cationic MB dye in presence of microwaveassisted NiFe204 NPs. 